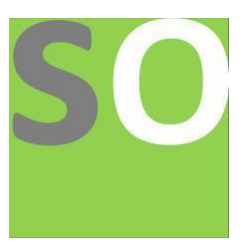

Article title: Design and Simulation of a Steam Turbine Generator using Observer Based and LQR Controllers Authors: mustefa jibril[1], Messay Tadese[2], Eliyas Alemayehu[3]

Affiliations: School of Electrical and Computer Engineering[1], Faculty of Electrical and Computer Engineering[2]

Orcid ids: 0000-0002-3165-2410[1]

Contact e-mail: mustefazinet1981@gmail.com

License information: This work has been published open access under Creative Commons Attribution License http://creativecommons.org/licenses/by/4.0/, which permits unrestricted use, distribution, and reproduction in any medium, provided the original work is properly cited. Conditions, terms of use and publishing policy can be found at https://www.scienceopen.com/.

Preprint statement: This article is a preprint and has not been peer-reviewed, under consideration and submitted to ScienceOpen Preprints for open peer review.

DOI: 10.14293/S2199-1006.1.SOR-.PPESF8J.v1

Preprint first posted online: 31 May 2020

Keywords: Steam turbine, Generator, Observer based controller, linear quadratic regulator, LQR 


\title{
Design and Simulation of a Steam Turbine Generator using Observer Based and LQR Controllers
}

\author{
Mustefa Jibril $^{1}$, Messay Tadese ${ }^{2}$, Eliyas Alemayehu Tadese ${ }^{3}$ \\ ${ }^{1}$ Msc, School of Electrical \& Computer Engineering, Dire Dawa Institute of Technology, Dire Dawa, \\ Ethiopia \\ ${ }^{2}$ Msc, School of Electrical \& Computer Engineering, Dire Dawa Institute of Technology, Dire Dawa, \\ Ethiopia \\ ${ }^{3}$ Msc, Faculty of Electrical \& Computer Engineering, Jimma Institute of Technology, Jimma, Ethiopia
}

\begin{abstract}
Steam turbine generator is an electromechanical system which converts heat energy to electrical energy. In this paper, the modelling, design and analysis of a simple steam turbine generator have done using Matlab/Simulink Toolbox. The open loop system have been analyzed to have an efficiency of $76.92 \%$. Observer based \& linear quadratic regulator (LQR) controllers have been designed to improve the generating voltage. Comparison of this two proposed controllers have been done for increasing the performance improvement to generate a 220 Dc volt. The simulation result shows that the steam turbine generator with observer based controller has a small percentage overshoot with minimum settling time than the steam turbine generator with LQR controller and the open loop system. Finally, the steam turbine generator with observer based controller shows better improvement in performance than the steam turbine generator with LQR controller.
\end{abstract}

Keywords: Steam turbine, Generator, Observer based controller, linear quadratic regulator

\section{Introduction}

A Steam Turbine is a mechanical system that takes thermal energy from pressurized steam and converted it into mechanical output. Because the turbine generates rotational speed motion, it is particularly used to drive electrical generators. a steam turbine gain power from a steam . As hot, steam passes through the turbine ' the blades will spinning. Steam expands and cools, convert most of the energy it contains. This steam continuously spins the blades. The blades converts the potential energy of the steam into kinetic energy. Steam turbines is used to drive a generator in order to produce electricity. In this paper, a steam turbine is designed to run a series wound DC generator. The shaft of the turbine is connected to the shaft of the generator with two gears at each side with a gear ratio between them.

\section{Mathematical Modelling}

Figure 1 shows the diagram of the steam turbine with a DC generator interconnection unit. 


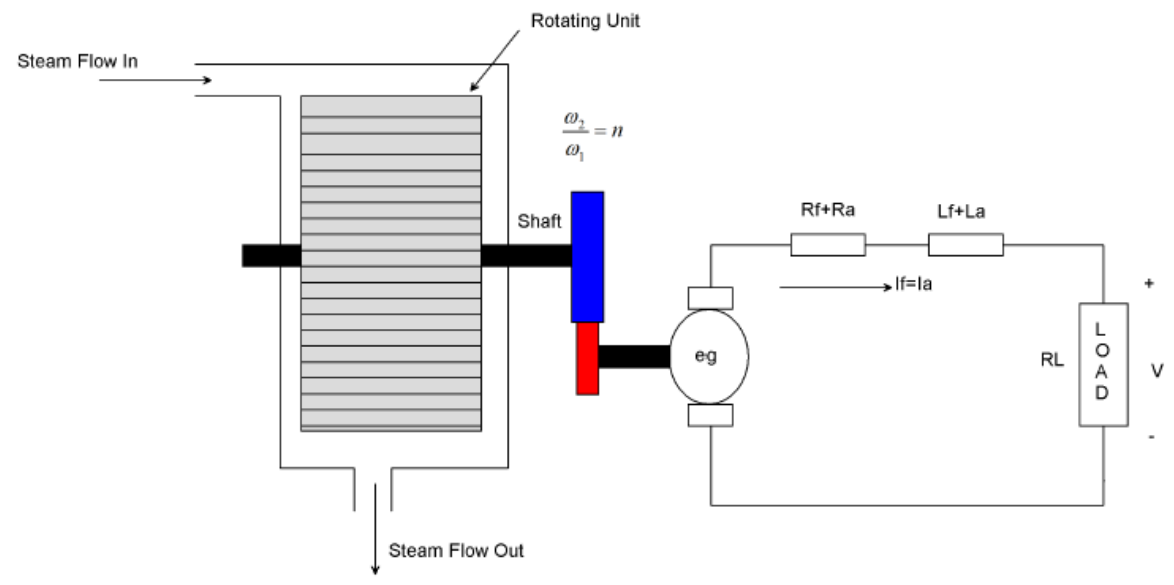

Figure 1 Steam turbine generator

The mechanical power developed by the steam turbine expressed by the equation:

$$
\frac{d W}{d t}=V \frac{d \rho}{d t}=F_{\text {in }}(t)-F_{\text {out }}(t)
$$

Where:

$W$ weight of steam in the steam turbine $[\mathrm{g}]$;

$V$ - Volume of steam turbine [m3];

$\rho$ - Density of steam $[\mathrm{g} / \mathrm{cm} 3]$;

$F$ - Steam mass flow rate $[\mathrm{g} / \mathrm{s}]$;

$t$-Time [sec.].

Assuming that the output mass flow rate of the steam turbine is proportional to the pressure in the turbine system:

$$
F_{\text {out }}=P \frac{F_{0}}{P_{0}}
$$

Where:

$P$ - Steam pressure in the system $[\mathrm{kPa}]$;

$P O$ - rated pressure;

$F O$ - rated output mass flow of the system

Assuming constant temperature in the system: 


$$
\frac{d \rho}{d t}=\frac{d P}{d t} \bullet \frac{\partial \rho}{\partial P}
$$

From equations (1) to (3), it results:

$$
F_{\text {in }}(t)-F_{\text {out }}(t)=V \frac{d P}{d t} \bullet \frac{\partial \rho}{\partial P}=V \bullet \frac{\partial \rho}{\partial P} \bullet \frac{d F_{\text {out }}}{d t}=\tau_{T} \frac{d F_{\text {out }}}{d t}
$$

Where

$$
\tau_{T}=V \bullet \frac{\partial \rho}{\partial P}-\text { Time constant }
$$

Then Equation (1) become

$$
\tau_{T} \frac{d F_{\text {out }}(t)}{d t}+F_{\text {out }}(t)=F_{\text {in }}(t)
$$

The steam mass flow rate is

$$
F(t)=F_{\text {in }}(t)-F_{\text {out }}(t)
$$

The turbine speed is integrally related to the steam flow rate:

$$
\omega_{1}(t)=\int F(t)=\int\left(F_{\text {in }}(t)-F_{\text {out }}(t)\right) d t
$$

Substituting Equation (5) for $F_{\text {out }}(t)$ into Equation (4) yields the transfer function between the input steam mass flow and the output turbine torque.

$$
\frac{\omega_{1}(s)}{F_{i n}(s)}=\frac{\tau_{T}}{\tau_{T} s+1}
$$

\subsection{Modelling of DC Generator}

The generated voltage is directly proportional to the generator input speed

$$
e_{g}=k_{1} \omega_{2}
$$

Where: $k 1$ is a speed proportional constant.

The generator input speed is the product of the gear ratio and the steam turbine output speed

$$
\omega_{2}=n \omega_{1}
$$

Therefore Equation (7) becomes

$$
e_{g}=k_{1} n \omega_{1}
$$


Then the transfer function between $F_{\text {in }}(s)$ and $e_{g}(s)$ become

$$
\frac{e_{g}(s)}{F_{\text {in }}(s)}=\frac{k_{1} n \tau_{T}}{\tau_{T} s+1}
$$

The equation of the generator is

$$
e_{g}(t)=\left(L_{f}+L_{a}\right) \frac{d i_{a}(t)}{d t}+\left(R_{f}+R_{a}+R_{L}\right) i_{a}(t)
$$

Now substituting Equation (9) in to Equation (10) yields

$$
k_{1} n \omega_{1}(t)=\left(L_{f}+L_{a}\right) \frac{d i_{a}(t)}{d t}+\left(R_{f}+R_{a}+R_{L}\right) i_{a}(t)
$$

Taking the Laplace transform and obtaining the transfer function the input speed and the output current yields

$$
\frac{I_{a}(s)}{\omega_{1}(s)}=\frac{n k_{1}}{s\left(L_{f}+L_{a}\right)+\left(R_{f}+R_{a}+R_{L}\right)}
$$

The output voltage is simply the product of load resistance times the armature current

$$
V(s)=R_{L} I_{a}(s)
$$

Now substituting Equation (13) in to Equation (12) yields

$$
\frac{V(s)}{\omega_{1}(s)}=\frac{n R_{L} k_{1}}{s\left(L_{f}+L_{a}\right)+\left(R_{f}+R_{a}+R_{L}\right)}
$$

Finally combining Equation (6) to Equation (14) yields to the transfer function between the input steam mass flows to the output generated voltage

$$
\frac{V(s)}{F_{\text {in }}(s)}=\frac{n R_{L} k_{1} \tau_{T}}{\left(\tau_{T} s+1\right)\left(s\left(L_{f}+L_{a}\right)+\left(R_{f}+R_{a}+R_{L}\right)\right)}
$$

The parameters of the system is shown in Table 1 below

Table 1 System parameters

\begin{tabular}{|l|l|l|l|}
\hline No & Parameters & Symbol & Value \\
\hline 1 & Time constant & $\tau_{T}$ & 2 second \\
\hline 2 & Speed proportional constant. & $k_{1}$ & $4 \mathrm{Vs} / \mathrm{rad}$ \\
\hline 3 & Gear ratio & $n$ & 4 \\
\hline 4 & Field winding inductance & $L_{f}$ & $3 \mathrm{H}$ \\
\hline
\end{tabular}




\begin{tabular}{|l|l|l|l|}
\hline 5 & Field winding resistance & $R_{f}$ & $2 \mathrm{ohm}$ \\
\hline 6 & Armature winding inductance & $L_{a}$ & $4 \mathrm{H}$ \\
\hline 7 & Armature winding resistance & $R_{a}$ & $4 \mathrm{ohm}$ \\
\hline 8 & Load resistance & $R_{L}$ & $8 \mathrm{ohm}$ \\
\hline
\end{tabular}

Numerically the transfer function become

$$
\frac{V(s)}{F_{\text {in }}(s)}=\frac{18}{s^{2}+2.5 s+1}
$$

The state space form of the transfer function is

$$
\begin{aligned}
& \dot{x}=\left(\begin{array}{cc}
-2.5 & -1 \\
1 & 0
\end{array}\right) x+\left(\begin{array}{l}
1 \\
0
\end{array}\right) u \\
& y=\left(\begin{array}{ll}
0 & 18
\end{array}\right) x
\end{aligned}
$$

\section{The Proposed Controllers Design}

3.1 Observer-Based Controller Design

The deal with the general case where only a subset of the states, or linear combinations of them, are obtained from measurements and are available to our controller. Such a guidelines is referred to as the output feedback problem.

The output is of the form

$$
y=C x+D u
$$

We shall examine a class of output feedback controllers constructed in two stages:

1. Contracting an observer | a system dynamics that is driven by the inputs and the outputs of the system, and yield an deliberation of its state variables;

2. Using the estimated state instead of the actual state in a estate response scheme.

The block diagram of the steam turbine generator system with the observer-based controller is shown in Figure 2 bellow. 


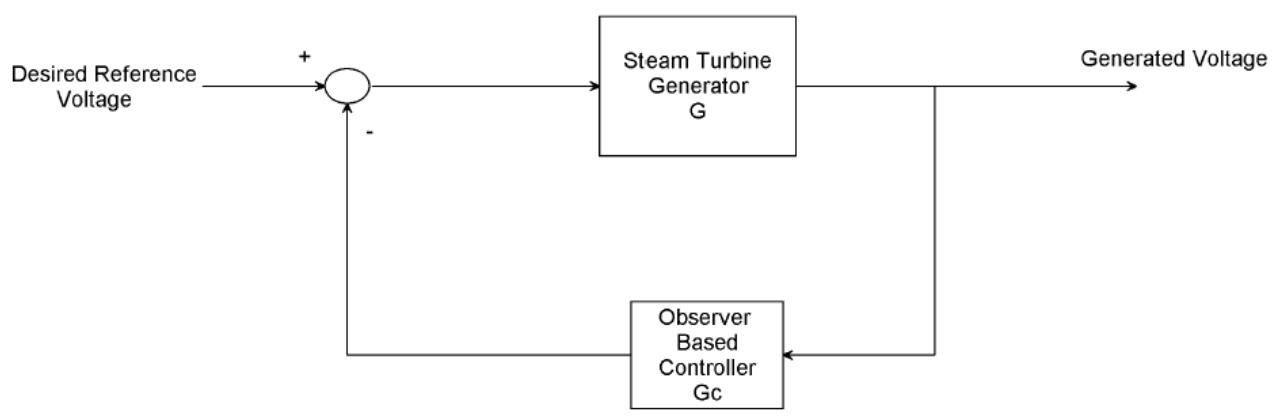

Figure 2 Block diagram of the steam turbine generator system with the observer-based controller The controller Gc(s) can be further derived in the following form:

$$
G_{c}(s)=I-K(s I-A+B K+H C)^{-1} B
$$

With its state space realization

$$
G_{c}(s)=\left[\begin{array}{cc}
A-B K-H C & B \\
-K & I
\end{array}\right]
$$

The controller Gc(s) in Equation (17) is called the observer-based controller, since the structural idiot of the observer is implicitly reflected within the controller.

Where the state space model of the plant, G, the state feedback gain vector $\mathrm{K}$, and the observer gain vector $\mathrm{H}$ are then returned, respectively.

We select the weighting matrix $\mathrm{Q}$ and $\mathrm{R}$ as

$$
Q=\left(\begin{array}{ll}
8 & 0 \\
0 & 8
\end{array}\right) \text { and } R=1
$$

And we select the observer gain vector as

$$
H=\left(\begin{array}{c}
2 \\
-0.5
\end{array}\right)
$$

And we obtain the state feedback gain vector $\mathrm{K}$ as

$$
K=\left[\begin{array}{ll}
1.7720 & 2
\end{array}\right]
$$

The observer-based controller state space representation become

$$
\begin{aligned}
& \dot{x}_{o}=\left(\begin{array}{cc}
-4.272 & -39 \\
1 & 9
\end{array}\right) x+\left(\begin{array}{c}
2 \\
-0.5
\end{array}\right) u_{o} \\
& y_{o}=\left(\begin{array}{ll}
1.772 & 2
\end{array}\right) x_{o}
\end{aligned}
$$




\subsection{LQR Controller Design}

LQR is a controller that gives the best possible achievement with respect to some given measure of performance. The realization measure is a quadratic function composed of state vector and manipulated input. The block diagram of the steam turbine generator with LQR controller is shown in Figure 2 below.

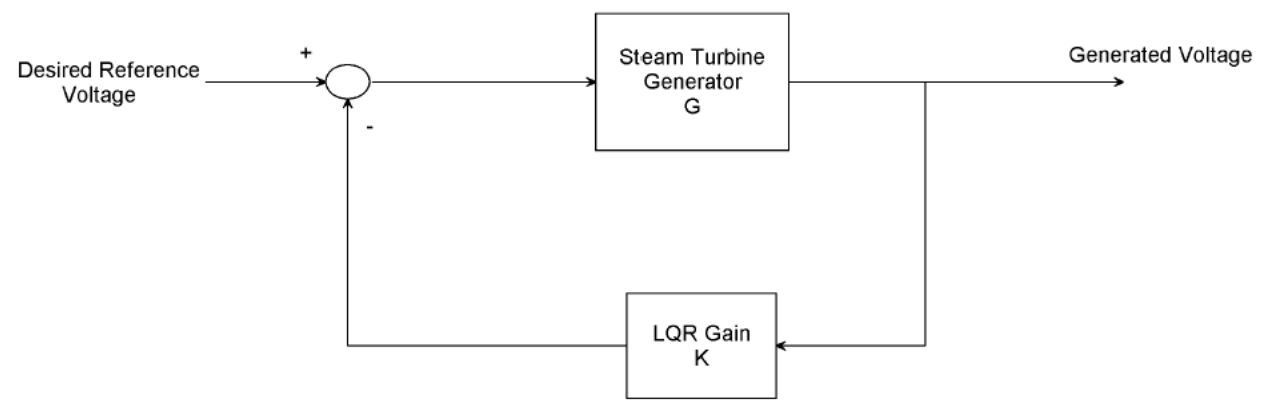

Figure 3 Block diagram of the steam turbine generator with LQR controller

Here we choose Q and R matrixes as

$$
Q=\left(\begin{array}{ll}
3 & 0 \\
0 & 3
\end{array}\right) \text { and } R=5
$$

The value of obtained feedback gain matrix $K$ of $L Q R$ is given by

$$
K=\left[\begin{array}{ll}
0.2166 & 0.2649
\end{array}\right]
$$

\section{Result and Discussion}

In this section, the open loop simulation of the generated voltage and power, the simulation of the performance comparison of the proposed controllers for generating a desired voltage is discussed below.

\subsection{Simulation of the open loop steam turbine generator voltage and power}

The open loop voltage and power generated for a steam mass flow of $5 \mathrm{~g} / \mathrm{s}$ input is shown in Figure 4 and Figure 5 respectively. 


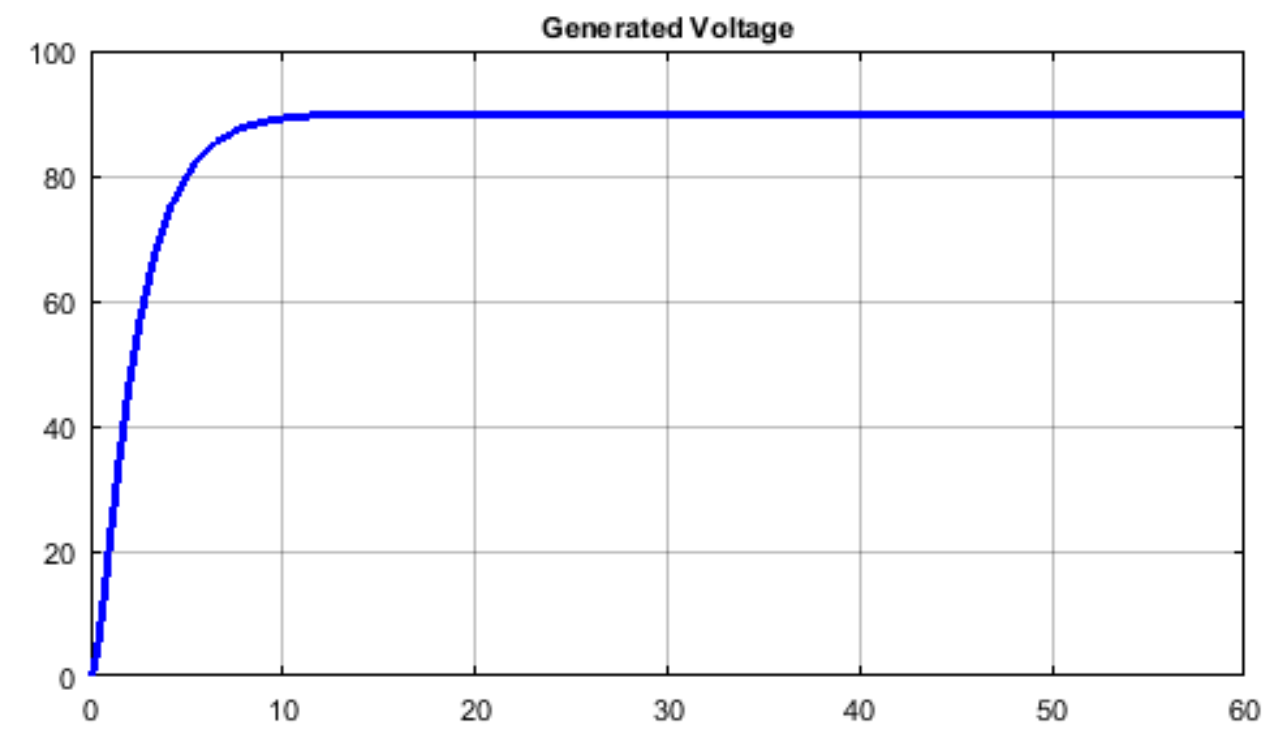

Time offset: 0

Figure 4 Open loop generated voltage

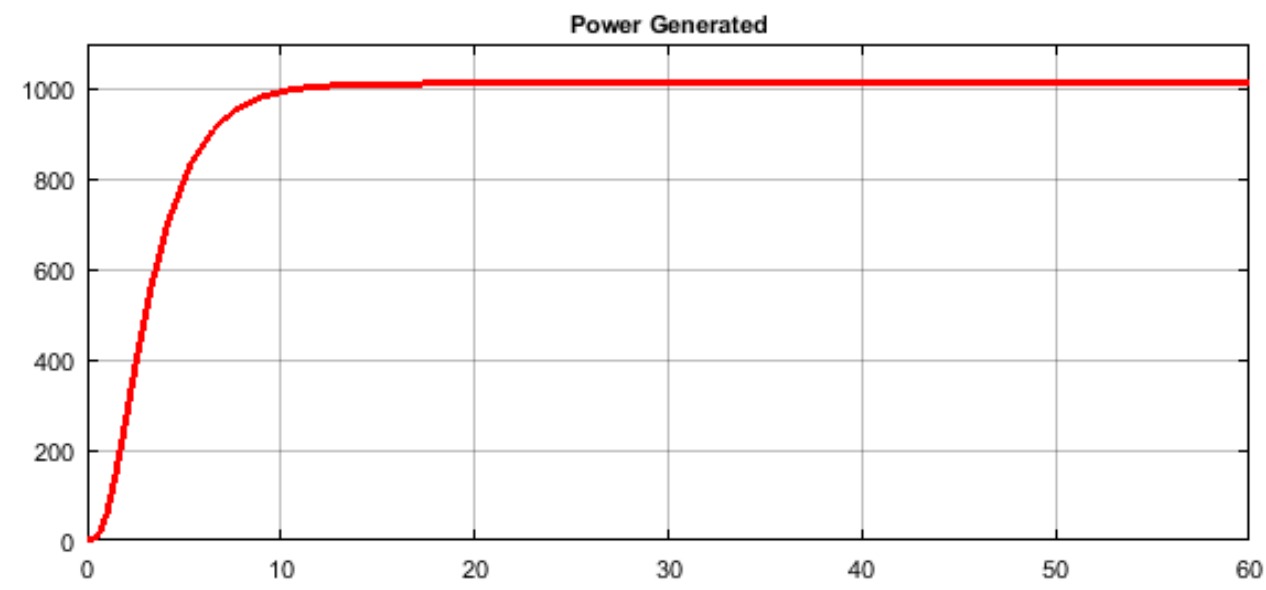

Time offset: 0

Figure 5 Open loop output power

As Figure 4 and Figure 5, in the first 10 seconds, the voltage increases from 0 to 90 volts and it reaches is steady state value of 90 volt and the output power is $1000 \mathrm{~W}$. The induced voltage in the armature circuit and the input power to the generator simulation result is shown in Figure 6 and Figure 7 respectively. 


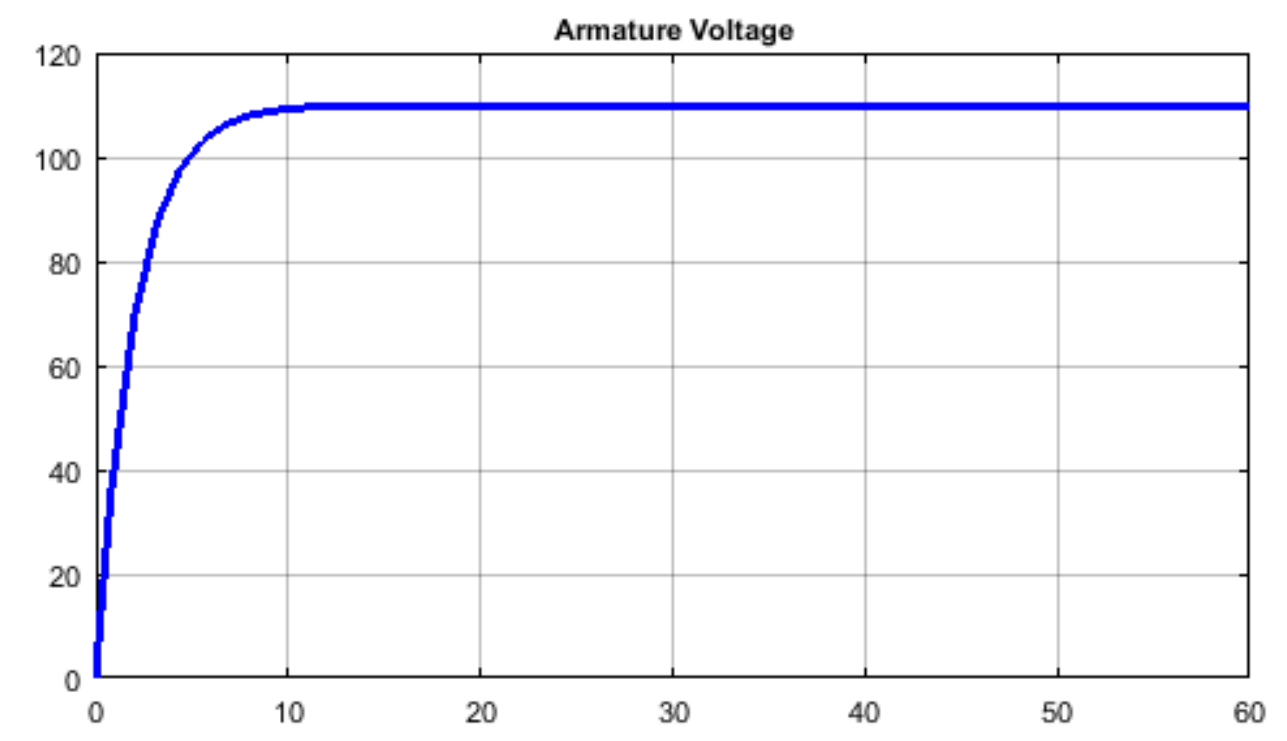

Time offset: 0

Figure 6 the induced voltage in the armature circuit

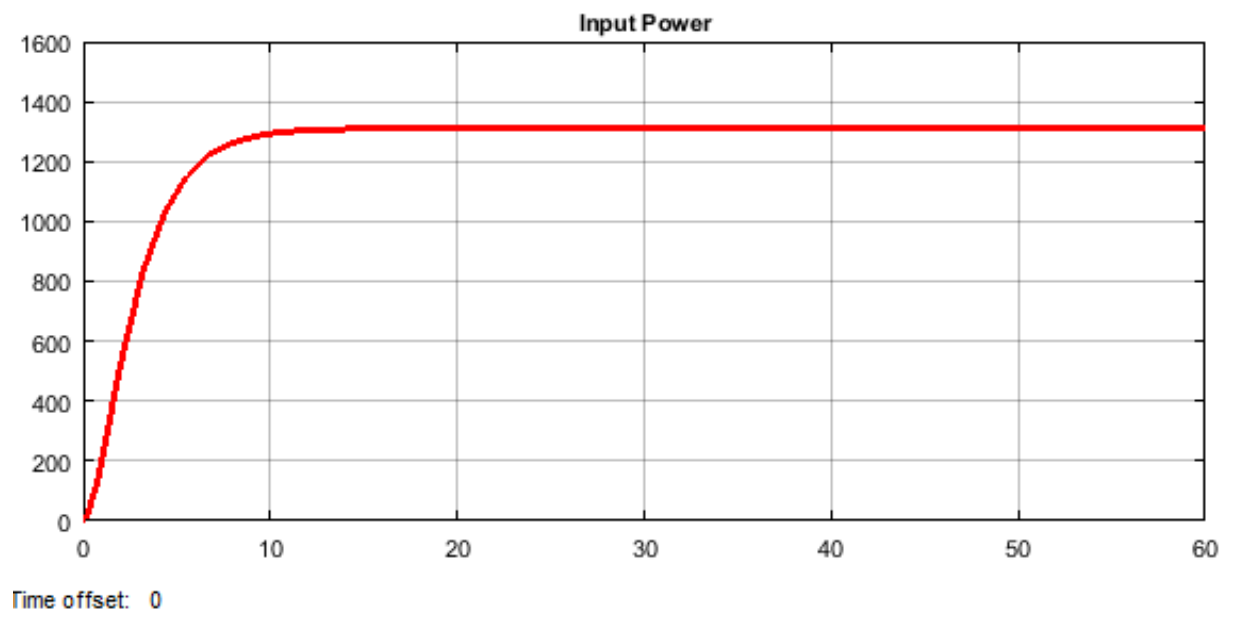

Figure 7 Input power

The efficiency of the system become

$$
\frac{\text { Output power }}{\text { Input power }} \times 100 \%=\frac{1000 \mathrm{~W}}{1300 \mathrm{~W}} \times 100 \%=76.92 \%
$$

\subsection{Comparison of the Steam Turbine Generator with Observer Based \& LQR Controllers for Generating a Desired Voltage}

The simulation result of the performance of the steam turbine generator with observer based $\&$ LQR controllers for generating a desired voltage of 220 Dc volt is shown in Figure 8 below. 


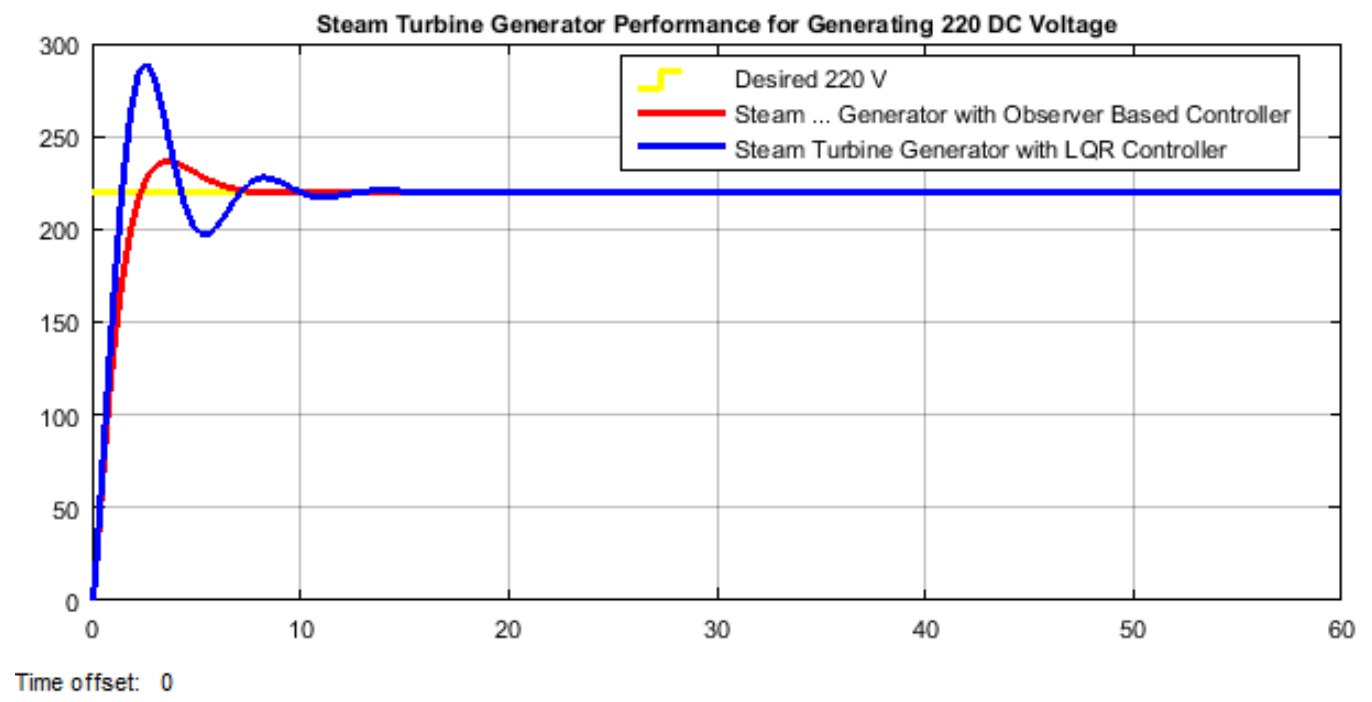

Figure 8 Performance of the steam turbine generator with observer based \& LQR controllers for generating a desired voltage of 220 Dc volt

As seen from Figure 8, the steam turbine generator with observer based controller has a small percentage overshoot and a settling time of 7 second which is better than the steam turbine generator with LQR controller and the open loop system.

\section{Conclusion}

In this paper, a simple steam turbine generator is modelled and designed using a series wound Dc generator. The open loop system is simulated for generated voltage, input and output power. For a steam mass flow of $5 \mathrm{~g} / \mathrm{s}$ the steam turbine generator generates a 90 volt with an output power of $1000 \mathrm{~W}$. The generator induced armature circuit voltage is simulated with an input power of $1300 \mathrm{~W}$. The efficiency of the simple steam turbine generator is $76.92 \%$. Comparison of the steam turbine generator with observer based \& LQR controllers for generating a desired voltage of 220 Dc volt have been simulated and the simulation result shows that the steam turbine generator with observer based controller has a small percentage overshoot and less settling time than the steam turbine generator with LQR controller and the open loop system. Finally the comparison and analysis result prove the effectiveness of the proposed steam turbine generator with observer based controller.

\section{Reference}

[1].K. Dinesh "Design and Structural Analysis of Steam Turbine" Journal of Engineering and Applied Sciences, Vol. 13, Issue 1, pp. 162-164, 2018.

[2].P. I. Onwuamaeze "Improving Steam Turbine Efficiency: An Appraisal" Research Journal of Mechanical Operations, Vol. 1, No. 1, pp. 24-30, 2018.

[3].Hosham S. et al. "Enhancement of Performance for Steam Turbine in Thermal Power Plants using Artificial Neural Network and Electric Circuit Design" Applied Computational Intelligence and Soft Computing, Vol. 2018, Article ID. 8042498, 9 pages, 2018. 
[4].V I Brezgin et al. "Improvement of Steam Turbine Operational Performance and Reliability with using Modern Information Technologies" Journal of Physics: Conference Series, Vol. 891, 2017.

[5].A. Sinan "Performance Analysis of a Steam Turbine Power Plant at Part Load Conditions" Journal of Thermal Engineering, Vol. 3, Issue 2, pp. 1121-1128, 2017.

[6].Li Sun et al. "Performance Modelling of New and Existing Steam Turbines" Ind. Eng. Chem. Res, Vol. 54, Issue 6, pp. 1908-1915, 2015.

[7]. G. Aravie et al. "Performance Modelling of Steam Turbine Performance using Fuzzy Logic Membership Functions" Journal of Applied Sciences and Environmental Management, Vol. 19, No. 1, 2015. 